\title{
Computational Results of Membership in R\&D Cooperation Networks: To Be or Not To Be in a Research Joint Venture
}

\author{
Duarte Leite $^{1,2}$, Pedro Campos ${ }^{1,2}$, and Isabel Mota ${ }^{1,3}$ \\ ${ }^{1}$ FEP (Faculty of Economics, University of Porto) \\ ${ }^{2}$ LIAAD - INESC, LA (Laboratory of Artificial Intelligence and Decision Support) \\ ${ }^{3}$ CEF-UP (Center for Economics and Finance at UP) \\ Rua Dr. Roberto Frias, 4200-464 Porto, Portugal \\ $\{100421015$, pcampos, imota $\}$ fep.up.pt
}

\begin{abstract}
In this study, we analyze firms' membership in R\&D (Research and Development) cooperation networks trough simulation methods. Our main research hypothesis is that the membership in cooperation networks is related to the degree of the knowledge spillover. The approach has two scenarios: cost symmetry and cost asymmetry. We first develop an analytical model with three stages: firstly, firms decide whether to participate in a cooperative research network; secondly they simultaneously choose the level of R\&D output, and finally they choose the level of output. Then we proceed with computational simulations to verify our hypothesis. From our results, we were able to conclude that cooperation leads to an improvement on RJV firms' position in the market as they produce more than others with the same production conditions. Additionally, cooperating firms have to spend fewer resources on research, which turns the network a tremendous success on the productive efficiency level.
\end{abstract}

Keywords: R\&D, cooperation, networks, spillover; simulation, RJV.

\section{Introduction}

In recent years, cooperation networks are one of the most appealing topics to study, gathering researchers from different scientific fields, such as biology, economy, management and computer science.

It is generally recognized that $\mathrm{R} \& \mathrm{D}$ activities have some public good features, as firms cannot fully appropriate the returns of their R\&D investments, due to the existence of $R \& D$ spillovers. As a result, $R \& D$ expenditures are usually less than socially optimal. For this reason, $R \& D$ cooperation frequently emerges, so as to internalize spillovers.

Cooperation in $\mathrm{R} \& \mathrm{D}$ is usually identified with research collaboration and it is often investigated in the context of two-stage oligopoly models in which firms make their R\&D decisions in a first pre-competitive stage and their quantity/price setting in a second stage. The most influential article on $R \& D$ cooperation is due to [8], who assumed that there are spillovers in R\&D output. Another prominent work is [10], 
which proposed spillovers in $R \& D$ expenditures and allowed for different $R \& D$ organization models that may involve $R \& D$ expenditures cartelization and/or full information sharing. Since these starting articles, a lot of scientific models emerged around the topic of $\mathrm{R} \& \mathrm{D}$ cooperation, providing numerous extensions to those original models (e.g. [12] and [11] on oligopolistic markets; [13] and [1] on R\&D spillovers; [7] and [9] on absorptive capacity; [3] and [4] on spillovers asymmetry; [6] on welfare). In this study we analyze the membership and profitability of cooperation networks. Our main research hypothesis is that the membership in a cooperation network is associated with the degree of $R \& D$ spillovers.

This approach tries to extend existing literature on R\&D cooperation networks by focusing on an oligopolistic scenario with asymmetric production costs and a previous membership stage. The work has been conducted in two parts, each of them divided in two steps. In the first part, we assume that firms are symmetric in what respects the marginal cost of production, $R \& D$ costs and the spillover outside the network. In the second part, we consider that firms may have different marginal costs of production. As for the steps, we propose developing (i) an analytical model, followed by (ii) a computational approach.

The main conclusions reached driven us to the fact that firms prefer $R \& D$ cooperation. Principally when there is cost asymmetry, we find that a network, for some level of spillover, would arise, containing some of the companies in the market. These companies benefit from higher profits and from R\&D from other companies which reduced their production costs. The number of firms keeps stable as the firms inside the RJV did not allow new companies to enter. This may allow us to infer that cooperation networks play a great role on firms' interaction and benefit some of them by giving a way to improve efficiency of companies that joined the RJV through a positive impact on internal productive

\section{Part I: R\&D Cooperation under Symmetric Marginal Costs}

By extending the model of [8] to an oligopolistic scenario with partial-industry agreements between cost-symmetric firms, we develop a three-stage game where firms decide about entering in the $R \& D$ cooperation network, then about its $R \& D$ expenditures and afterwards they compete in the output market.

There are $n$ firms that produce a homogeneous output, whose inverse demand function is given by:

$$
P=a-b Q
$$

where the parameter $a$ captures the market size and $b$ is a constant. $Q$ is the total output given by the expression:

$$
Q=\sum_{i=1}^{n} q_{i}(a, b>0 \text { and } Q \leq a / b) .
$$

As it is typical in $R \& D$ cooperation models (e.g. [8]), we assume that $R \& D$ output is cost reducing through an additive formulation, that is: 


$$
c_{i}=\overline{\alpha_{i}}-x_{i}-\beta \sum_{j \neq i}^{n} x_{j} .
$$

where $c_{i}$ is firm i's marginal cost of production, $\overline{\alpha_{i}}$ accounts for stand-alone marginal costs $\left(0<\overline{\alpha_{i}}<\mathrm{a}\right), x_{i}$ measures firm i's R\&D output and $\beta$ is the spillover $(0 \leq \beta \leq 1)$. Additionally, and as in [8], we consider a specific functional form for the R\&D cost function:

$$
C\left(x_{i}\right)=0,5 \gamma x_{i}^{2} .
$$

where $\gamma>0$ represents the $R \& D$ cost. The profit of firm $i$ is then given by:

$$
\pi_{i}=\left(P-c_{i}\right) q_{i}-C\left(x_{i}\right)=\left(a-b \sum_{j=1}^{n} q_{j}-\overline{\alpha_{i}}+x_{i}+\beta \sum_{j \neq i}^{n} x_{j}\right) q_{i}-0,5 \gamma\left(x_{i}\right)^{2} .
$$

where $q_{i}$ is firm i's output. The game is organized in three stages, as follows:

(i) In the first stage (membership stage), firms decide whether to participate (or not) in a cooperative research network. For simplicity, we will assume that within the cooperative network, the degree of information sharing is set at its maximum level $(\beta=1)$, a structure known as the Research Joint Venture (RJV) [10]. Additionally, we will consider that insiders can obstruct the entry of an additional firm if it reduces their profits, while an outside firm will join the RJV only if it increases its profits. The conditions are defined according to those usually adopted in the literature (e.g. [11]; [2]): the conditions are the following, for a RJV of size m:

$$
\begin{gathered}
\pi_{i}^{m}(m) \geq \pi_{i}^{m}(m-1) . \\
\pi_{i}^{m}(m) \geq \pi_{i}^{n-m}(m-1) . \\
\pi_{i}^{m}(m) \geq \pi_{i}^{m}(m+1) \text { or } \pi_{i}^{n-m}(m) \geq \pi_{i}^{m}(m+1) \text { or both } .
\end{gathered}
$$

where $\pi_{i}^{m}(\mathrm{t})$ represents the profit of an insider and $\pi_{i}^{n-m}(\mathrm{t})$ the profit of an outsider when the RJV is of size t. $\pi_{i}^{m}(\mathrm{~m})$ represents the average profit of firms in network of size $\mathrm{m}$ and $\pi_{i}^{m}$ (m-1) represents the average profit of firms in network of size $\mathrm{m}$, not taking into account one specific firm.

(ii) In the second stage (development stage), firms simultaneously choose the level of R\&D output, independently or under cooperation. If firms cooperate, then they will coordinate $R \& D$ output in order to maximize their joint profits.

(iii) At last, in the production stage, firms simultaneously choose the level of output through Cournot competition.

Due to the complexity of the analytical solution for the equilibrium R\&D output, we use numerical simulations to model the game described before. We were able to arrive to some interesting conclusions regarding the behaviour of companies in terms of network formation. Simulation results are presented in Table 1. 
Table 1. Results of the simulation for $n=5$ firms and for different values of Beta $(\beta)$

\begin{tabular}{lrrrrrr}
\hline & & & & & & \\
\hline Marginal cost=50 and R\&D cost $(\gamma)=50$ & - & 0.2 & 0.4 & 0.6 & 0.81 & \multicolumn{1}{c}{0.91} \\
Beta $(\beta)$ & 48.90 & 49.58 & 50.09 & 50.42 & 50.58 & 50.59 \\
RJV Profits & 24.75 & 24.92 & 25.06 & 25.17 & 25.25 & 25.28 \\
Non-RJV profits & 0.05 & 0.11 & 0.11 & 0.11 & 0.11 & 0.11 \\
RJV R\&D output & 0.14 & 0.11 & 0.09 & 0.07 & 0.05 & 0.04 \\
Non-RJV R\&D output & & & & & & \\
Marginal cost=50 and R\&D cost $(\gamma)=90$ & & & & & & \\
Beta $(\beta)$ & - & 0.2 & 0.4 & 0.6 & 0.81 & 0.91 \\
RJV Profits & 49.34 & 49.75 & 50.05 & 50.25 & 50.35 & 50.35 \\
Non-RJV profits & 24.85 & 24.95 & 25.03 & 25.10 & 25.15 & 25.17 \\
RJV R\&D output & 0.03 & 0.07 & 0.07 & 0.07 & 0.07 & 0.07 \\
Non-RJV R\&D output & 0.08 & 0.07 & 0.06 & 0.04 & 0.03 & 0.02 \\
\hline
\end{tabular}

Firstly, we may observe that all firms outside the RJV want to make part of the network and, simultaneously, insiders do not obstruct the entry of those additional firms. There is stability when all firms are inside the network and therefore there is no entrance or exit of firms to and from the RJV. Whatever is the number of companies in the market and for every spillover levels, companies will sooner or later enter in the RJV and there will be a huge cooperation network between all companies in the market, after interaction starts.

From our computational exercise, we first observe that there is a direct relationship between the R\&D spillover outside the network $(\beta)$ and firms' profit (Figure 1). In fact, we may conclude that an increase of the R\&D spillover outside the RJV will make firms to benefit from other firms' knowledge, and, therefore, to increase its profits. And this is true for both RJV and non-RJV firms, while in the first case, profits are higher due to a maximum spillover among cooperating firms. A correlation coefficient of 0,997 between the spillover and firms' profit was found to be statistically significant.

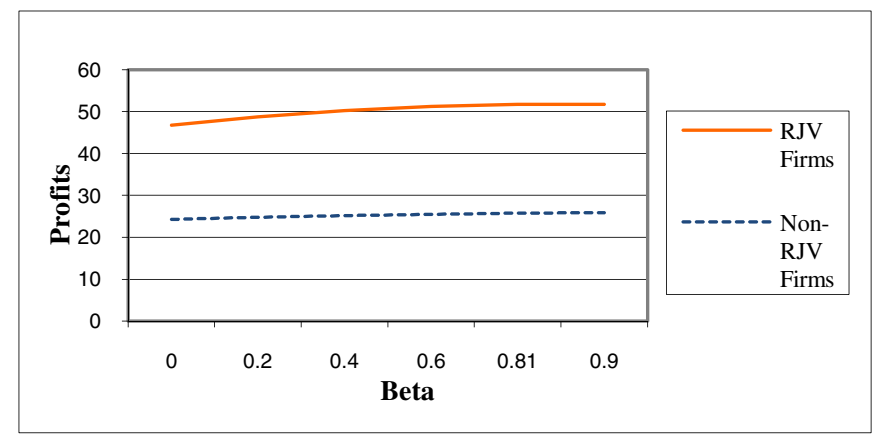

Fig. 1. Profits evolution with the spillover between non-cooperating firms (beta)

Additionally, when we focus on the R\&D investment, we observe that it is higher for non-cooperating firms when compared with cooperating firms, except for a high degree of information sharing among non-cooperating firms (Figure 2). At the same 
time, we observe that for non cooperating firms, there is an inverse relationship between the level of knowledge spillover and the investment in R\&D. This result is rather intuitive: higher degree of information sharing means lower appropriateness of $R \& D$ efforts and, therefore, lowers R\&D investments.

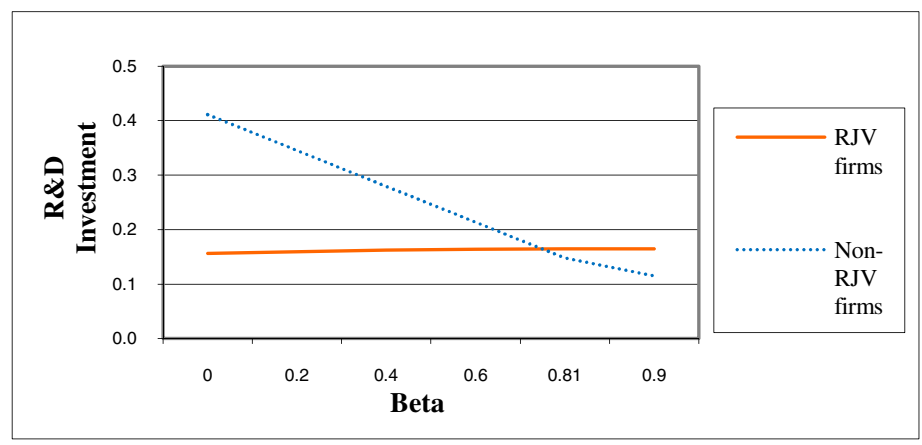

Fig. 2. R\&D output evolution with the spillover between non-cooperating firms

We can also see that whenever we repeat the simulation for different number of firms in the market $(n)$, we observe that as $n$ increases, the R\&D output decreases. This fact can be explained by the inverse relationship between the R\&D output and the spillover. Therefore, as the number of firms in the market increases the R\&D output decreases due to the fact that the spillover is greater for larger number of firms in the market and the need for R\&D output is inferior.

\section{Part II: R\&D Cooperation under Asymmetric Marginal Costs}

The results given in the previous simulation were very interesting and gave some insights on the behaviour of firms. However, it seems worthwhile to consider a more appealing framework where there is cost asymmetry between firms, giving literature a better perspective through simulation.

So, now we considered both equations 1, 2 and 3, that have been introduced in part I, while equation ( $\left.3^{\prime}\right)$ captures the existence of diverse marginal costs of production between firms:

$$
c_{i}=\alpha_{i}-x_{i}-\beta \sum_{j \neq i}^{n} x_{j} .
$$

where $\alpha_{i}$ accounts for stand-alone marginal costs $\left(0<\alpha_{i}<a\right), x_{i}$ measures firm $i$ 's $\mathrm{R} \& \mathrm{D}$ output and the $\mathrm{R} \& \mathrm{D}$ spillover has the same properties, $\beta \in[0,1]$. As written before, it will be assumed that there are diminishing returns to $R \& D$ expenditures, that is, $C^{\prime}\left(x_{i}\right)>0$ and $C^{\prime \prime}\left(x_{i}\right)>0$.

The profit function has changed so that it reflected the differences on marginal costs of production between firms: 


$$
\pi_{i}=\left(P-c_{i}\right) q_{i}-C\left(x_{i}\right)=\left(a-b \sum_{j=1}^{n} q_{j}-\alpha_{i}+x_{i}+\beta \sum_{j \neq i}^{n} x_{j}\right) q_{i}-0,5 \gamma\left(x_{i}\right)^{2} .
$$

The same three-stage game used in Part I is proposed: firms decide about cooperation membership, R\&D and then about the output. However, and in order to find different structures and the responses of network formation to these types of frameworks, we assume three different decision criteria on the members' decision of letting nonmembers enter or not the network. Each one of these three options is used to find out how network formation can show different features by changing this condition. Following the literature (e.g. [11]; [2]), we add these new three criteria:

(1) The average profit inside the network increases with the entrance of a nonmember firm;

(2) The profit of the firm that will enter is higher than the network's average profit;

(3) The profit of the firm with highest income (a kind of "leader" firm) remains the same or increases with the entrance of a new member.

From the simulation considered in Part II we could observe several aspects that differ from the previous simulation in Part I. As regarding firms' cost asymmetry, it is possible to say that, in general, firms with low marginal production costs have higher profits, produce more output and are those who do more research, which means that they have higher R\&D output. We then test some combinations of firms, with different marginal costs of production, in order to evaluate if there are some changes in the firms within the network. Not in all combinations but in most of them, network stability occurs for low levels of spillover. This means that when the spillover reaches a lower level, firms prefer to join the R\&D network in order to benefit from a total share of research output and then have less production costs and so higher profits, contrasting with same background firms. The network advantages make possible firms with same marginal costs of production have different profits, as the ones inside the RJV reduce more their production costs due to R\&D output spread between them. That is why their profits are normally superior.

A relevant fact is that some networks are formed by a mix of firms with better and worse production skills. Therefore, with some exceptions, cooperation takes place not only between firms with high or low efficiency, but they are formed by middle marginal cost companies or joint "extreme marginal cost" firms where the ones with the lowest production efficiency are the most benefited by cost reduction. On the profits issue, we can state that they tend to diminish with the fall of the spillover since the marginal production costs are not so reduced by efficiency achievements. Only if the firm belongs to the RJV then its profit increases in the first moment when the company joins the network. From the example in Table 2, where we show one of the simulation results, we see that firms that enter the RJV increase greatly their profits, while the others that have the same level of profits maintain that level and watch them decreasing when spillover increases. Mostly important, we also observe that firms with different levels of marginal costs (reflected in the different levels of profits), join together to form a strong and beneficial network. As we can see, from the three groups of firms here, we have in the network, for a spillover of 0.27 , one firm from the first group and two from the third group. 
Table 2. Firm's profits determined on the simulation experiments made

\begin{tabular}{clllllllll}
\hline & \multicolumn{7}{c}{ Firms } \\
\hline Spillovers & $\mathbf{1}^{\text {st }}$ & $\mathbf{2}^{\text {nd }}$ & $\mathbf{3}^{\text {rd }}$ & $\mathbf{4}^{\text {th }}$ & $\mathbf{5}^{\text {th }}$ & $\mathbf{6}^{\text {th }}$ & $\mathbf{7}^{\text {th }}$ & $\mathbf{8}^{\text {th }}$ & $\mathbf{9}^{\text {th }}$ \\
$\mathbf{0 7 5}$ & 419 & 421 & 419 & 110 & 110 & 110 & 649 & 649 & 649 \\
$\mathbf{0 , 5}$ & 417 & 419 & 417 & 109 & 109 & 109 & 646 & 646 & 646 \\
$\mathbf{0 , 3}$ & 416 & 416 & 416 & 109 & 108 & 108 & 645 & 645 & 645 \\
$\mathbf{0 , 2 9}$ & 415 & 415 & 415 & $\mathbf{1 1 2}$ & 108 & 108 & $\mathbf{6 5 5}$ & $\mathbf{6 5 5}$ & 644 \\
$\mathbf{0 , 2 7}$ & 415 & 415 & $\mathbf{4 2 6}$ & 107 & 107 & 107 & $\mathbf{6 5 7}$ & $\mathbf{6 5 7}$ & 643 \\
$\mathbf{0 , 1}$ & 412 & 412 & $\mathbf{4 2 8}$ & 106 & 106 & 106 & $\mathbf{6 5 9}$ & $\mathbf{6 5 9}$ & 640 \\
$\mathbf{0 , 0 3}$ & 412 & 412 & $\mathbf{4 2 8}$ & 106 & 106 & 106 & $\mathbf{6 6 0}$ & $\mathbf{6 6 0}$ & 639 \\
\hline
\end{tabular}

These results are confirmed by empirical literature. [5] study the effects of incoming spillovers and appropriability on having cooperation. Using data from Belgium they found that incoming spillovers have a positive and significant effect on the probability of firms cooperating. They also find that the higher appropriability, the higher the probability of network cooperation. However, they show that it may depend on the kind of partners firms deal with. In addition, some non-spillover determinants of cooperation are also examined, and they found that larger firms are more likely to cooperate, which is partially confirmed in our study as the results show that firms with lower marginal costs usually engage easily in cooperation.

Statistical tests were used in order to corroborate the relationships and the effects of the variables in the experiments. One-way ANOVA has been computed, considering the effect of several values of the marginal cost (here used as a factor/qualitative variable), over the profit of the firms. The overall null hypothesis has been rejected, meaning that different marginal costs produce different levels of profits in the firms. Post-hoc multiple comparisons tests (Tuckey HSD) have been performed and we were able to conclude that lower marginal costs are associated with higher profits.

We have also compared the profits between networked and non networked firms. The result of the Mann-Whitney test is that statistically significant differences exist between those kinds of firms: firms in networks have higher profits than those not in networks.

Concerning $R \& D$ output, we can notice that it has a propensity to increase as a result of a diminishing spillover (Table 3). Nevertheless, if some firms start to cooperate and their R\&D output decreases, as a result of the full knowledge sharing benefit that the network agreement provides. As they will share all the research they make, they will not spend so many resources on $R \& D$ and then their private $R \& D$ output decreases. Continuing using the previous example, we see that R\&D output decreases with the entrance in the network but it still increases if the spillover decreases outside the network. This happens because firms will have to invest more so that they can maintain themselves producing in the market, and also because their investment will almost not flow to other firms outside the network. Since the spillover is lower, which decreases free riding behavior, firms outside the network need to increase their R\&D output. 
Table 3. Firm's R\&D output determined on the simulation experiments made

\begin{tabular}{clllllllll}
\hline & & \multicolumn{1}{c}{ Firms } \\
\hline Spillovers & $\mathbf{1}^{\text {st }}$ & $\mathbf{2}^{\text {nd }}$ & $\mathbf{3}^{\text {rd }}$ & $\mathbf{4}^{\text {th }}$ & $\mathbf{5}^{\text {th }}$ & $\mathbf{6}^{\text {th }}$ & $\mathbf{7}^{\text {th }}$ & $\mathbf{8}^{\text {th }}$ & $\mathbf{9}^{\text {th }}$ \\
\hline $\mathbf{0 , 7 5}$ & 0,06 & 0,06 & 0,06 & 0,03 & 0,03 & 0,03 & 0,08 & 0,08 & 0,08 \\
$\mathbf{0 , 5}$ & $\mathbf{0 , 1 0}$ & 0,10 & 0,10 & 0,05 & 0,05 & 0,05 & 0,13 & 0,13 & 0,13 \\
$\mathbf{0 , 3}$ & 0,14 & 0,14 & 0,14 & 0,07 & 0,07 & 0,07 & 0,17 & 0,17 & 0,17 \\
$\mathbf{0 , 2 9}$ & $\mathbf{0 , 1 4}$ & 0,14 & $\mathbf{0 , 1 4}$ & $\mathbf{0 , 0 6}$ & 0,07 & 0,07 & $\mathbf{0 , 1 3}$ & $\mathbf{0 , 1 3}$ & 0,17 \\
$\mathbf{0 , 2 7}$ & $\mathbf{0 , 1 4}$ & 0,14 & $\mathbf{0 , 1 1}$ & 0,07 & 0,07 & 0,07 & $\mathbf{0 , 1 4}$ & $\mathbf{0 , 1 4}$ & 0,17 \\
$\mathbf{0 , 1}$ & $\mathbf{0 , 1 7}$ & 0,17 & $\mathbf{0 , 1 3}$ & $\mathbf{0 , 0 9}$ & 0,09 & 0,09 & $\mathbf{0 , 1 6}$ & $\mathbf{0 , 1 6}$ & 0,21 \\
$\mathbf{0 , 0 3}$ & $\mathbf{0 , 1 8}$ & $\mathbf{0 , 1 8}$ & $\mathbf{0 , 1 4}$ & $\mathbf{0 , 0 9}$ & 0,09 & 0,09 & $\mathbf{0 , 1 8}$ & $\mathbf{0 , 1 8}$ & 0,22 \\
\hline
\end{tabular}

Finally, regarding the output or production level (q), we see that it depends on the type of firms existing in the network, more precisely, the asymmetry between firms' marginal cost of production. In fact, when there are firms with different levels of efficiency, those who are more productive normally tend to increase their output, while the less efficient ones see their output being reduced. However, this situation changes if a network arises: in this case, cooperating firms produce more than in a non-cooperation scenario, mainly if compared with other firms with the same parameter profile.

Concerning the interactions between network formation and stability, we know that companies inside the network have, in this algorithm, the last word on letting or not outside firms to enter in it. Three different entering criteria were defined that turned different numerical results mostly significant on network stability, as it was explained (Figure 3). Considering the above mentioned criteria, the second one, where outsiders enter the network if their initial profit is higher than the average profit, originates the highest frequency of networks. It contrasts with all other criteria, where the last criterion is the one with worse results in what respects network formation.

Generally it is possible to visualize which criterion is more flexible, making the entrance easier to new companies inside the RJV. As we can see in Fig. 3, the spillover necessary to build a network is higher for criterion 2, followed by criterion 1 and then 3 , the least advantageous criterion. Considering the third criterion, only in four experiments a network was formed. On the other hand, in the experiments with the second criterion there is always a network formed. Therefore, as explained above, circumstances necessary to generate a RJV are less tough in the second criterion than for the other possible criteria.

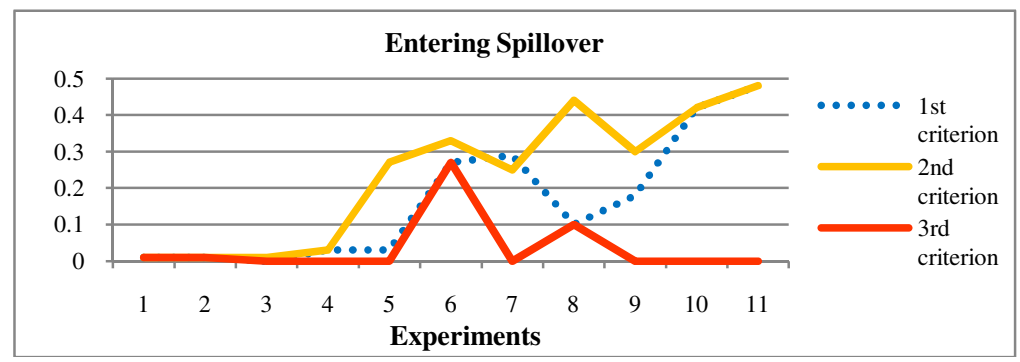

Fig. 3. Spillover value needed to form a network for each criterion 


\section{Final Remarks}

In this study, we analyzed the membership in $R \& D$ cooperation networks and its impact on some economic indicators. Our main research hypothesis was that the membership in cooperation networks is related to the degree of the knowledge spillover. We first developed an analytical model where we considered that production costs were symmetric between all companies in the market. We then used numerical simulations to verify our hypothesis. The conclusions obtained were that the profit of firms in the network is higher than the corresponding profit outside the network. We also observed that as the number of firms in the market increases the R\&D output decreases due to the fact that the spillover is greater for larger number of firms in the market and the need for R\&D output is inferior.

However, all firms entered in the network independently of the environment they faced in the market. So, in order to get close to the reality, a new approach was attempted by introducing cost asymmetry. By doing this we could find that a network, for some level of spillover, would arise but without all companies entering it. Only some would be able to join together and benefit from R\&D cooperation and then benefit from higher profits and from $R \& D$ of other companies which reduced their production costs. The number of firms kept stable as the firms inside the RJV did not allow new companies to enter, maintaining cooperation benefits just for them.

Nevertheless, networks also depended on how companies manage the RJV. The formation and maintenance of a network depended on what were the entrance and exit decisions defined by firms. As seen before, there were types of decisions that leaded to easier network formation and others did not, depending on what were the minimum requirements for companies to belong to the network. By comparing the two approaches we reached the conclusion that the second was more close to reality. In both cases the number of firms in the network kept stable but on the first model companies entered into the network regarding any kind of situation while in the second model there was entrance only for some levels of spillover and in only some circumstances making the simulation more alike to reality.

But, whatever the approach was, the gains to companies that joined the network were higher. And its impact on profits was showed vital to their performance on the model.

\section{References}

1. Amir, R., Wooders, J.: One-Way Spillovers, Endogenous Innovator/Imitator Roles, and Research Joint Ventures. Games and Economic Behavior 31(1), 1-25 (2000)

2. Atallah, G.: Information sharing and the stability of cooperation in research joint ventures. Economics of Innovation and New Technology 12(6), 531-554 (2003)

3. Atallah, G.: Research Joint Ventures Cartelization with Asymmetric R\&D Spillovers. Economics Bulletin 12(18), 1-11 (2005)

4. Atallah, G.: Research Joint Ventures with asymmetric spillovers and symmetric contributions. Economics of Innovation and New Technology 16(7), 559-586 (2007)

5. Cassiman, B., Veugelers, R.: R\&D Cooperation ans Spillovers: Some Empirical Evidence from Belgium. The American Economic Review 92(4), 1169-1184 (2002) 
6. Cellini, R., Lambertini, L.: Dynamic R\&D with Spillovers: Competition vs cooperation. Journal of Economic Dynamics \& Control 33(3), 568-582 (2009)

7. Cohen, W.M., Levinthal, D.A.: Innovation and Learning: The Two Faces of R\&D. Economic Journal, Royal Economic Society 99(397), 569-596 (1989)

8. d'Aspremont, C., Jacquemin, A.: Cooperative and Noncooperative R\&D in Duopoly with spillovers. American Economic Review 78(5), 1133-1137 (1988)

9. Kamien, M.I., Zang, I.: Meet me halfway: research joint ventures and absorptive capacity. International Journal of Industrial Organization 18(7), 995-1012 (2000)

10. Kamien, M.I., Muller, E., Zang, I.: Research Joint Ventures and R\&D Cartels. American Economic Review 82(5), 1293-1306 (1992)

11. Poyago-Theotoky, J.: Equilibrium and Optimal Size of a Research Joint Venture in an Oligopoly with Spillovers. Journal of Industrial Economics 43(2), 209-226 (1995)

12. Suzumura, K.: Cooperative and Noncooperative R\&D in an Oligopoly with Spillovers. American Economic Review 82(5), 1307-1320 (1992)

13. Vonortas, N.S.: Inter-firm cooperation with imperfectly appropriable research. International Journal of Industrial Organization 12(3), 413-435 (1994) 